Portland State University

PDXScholar

6-16-2021

\title{
The Prevalence of Mental Health Disorders and Deficits in Individuals With and Without Siblings
}

Samantha Villanueva

Portland State University

Follow this and additional works at: https://pdxscholar.library.pdx.edu/honorstheses

Part of the Child Psychology Commons, Developmental Psychology Commons, and the Personality and Social Contexts Commons

Let us know how access to this document benefits you.

\section{Recommended Citation}

Villanueva, Samantha, "The Prevalence of Mental Health Disorders and Deficits in Individuals With and Without Siblings" (2021). University Honors Theses. Paper 1103.

https://doi.org/10.15760/honors.1130

This Thesis is brought to you for free and open access. It has been accepted for inclusion in University Honors Theses by an authorized administrator of PDXScholar. Please contact us if we can make this document more accessible: pdxscholar@pdx.edu. 
The Prevalence of Mental Health Disorders and Deficits in Individuals With and Without Siblings

by

Samantha Villanueva

An undergraduate honors thesis submitted in partial fulfillment of the

\author{
requirements for the degree of \\ Bachelor of Science \\ in \\ University Honors \\ and \\ Psychology
}

Thesis Adviser

Jessica Tipsord, $\mathrm{PhD}$

Portland State University 
Abstract 3

$\begin{array}{lr}\text { Introduction } & 4\end{array}$

Mental Health Deficits in Children and Adolescents With and Without Siblings 5

The Effects of Trauma Within Childhood Sibling Dynamics, or a Lack Thereof 7

$\begin{array}{lr}\text { Lasting Influences on Mental Health } & 8\end{array}$

$\begin{array}{lr}\text { Primary Prevention Programs } & 10\end{array}$

$\begin{array}{ll}\text { Discussion } & 11\end{array}$ 


\begin{abstract}
The goal of this thesis is to understand how having siblings could affect mental wellbeing in individuals. Within the framework of a literature review, I examined multiple aspects of mental well-being with regard to siblings: 1) if having siblings could be a precursor for behavioral or developmental patterns in children 2) how trauma affects only children and individuals with siblings differently 3 ) long-term effects of sibling count once children reached adulthood 4) biases from clinical perspectives and prevention programs to combat these. Upon conclusion, only children were often noticed to struggle with mental health and certain socialization, although researchers noted that these cases could be dependent on confounding factors such as class and socialization outside of the home. Additionally, long-term effects were noted in terms of mental well-being, as only children were more susceptible to struggling with their parent and/or parents passing away.
\end{abstract}




\section{Introduction}

Much of what basic Psychology teaches young adults regarding familial structures in relation to the child is based upon the birth order theory and "only child syndrome," in which children with and without siblings are categorized by defining traits in concise, yet confining, terms (Adler, 1928; Higuera, 2019). Proceeding through my own educational route, I never felt comfortable applying these theories because of the cultural and social discrepancies that may disrupt these very terms, given that each home and each individual adds to the overarching development for the child at hand. One may be able to define these children based on birth order: the oldest is more "responsible," the middle child goes "unnoticed," and the youngest, the deviant. The only child is thought to be diligent, sociable, and successful within their future careers due to the attentive nature of their parents without competition between siblings. The only child syndrome also attributes negative qualities within the individual such as narcissism and controlling behavior. How do we attribute these simplistic categorizations to a family with parents that do not encourage the fostering of mental well-being or socialization? To assume that birth order theory and only child syndrome explain the mental health of individuals is to deny any understanding of how sibling dynamics, peer relationships, and trauma may contribute. It is with this understanding that I proceed through my own research of these other variables, ones that play a role in the mental well-being of these children as they develop into early adulthood and beyond. One of the main aspects of my research will be on examining these variables through the lens of trauma within or outside of the household. Therefore, my question upon conducting this literature review is: how does trauma specifically affect children in only-child homes versus children with siblings, and could a lack of siblings make these adolescents more 
vulnerable to mental health disorders and deficits in the future? Additionally, what are the preventative actions that can be taken to disrupt this?

\section{Mental Health Deficits In Children and Adolescents With and Without Siblings}

To properly understand the effects of being raised within an only-child home, the examination of its antecedent is required, that being how siblings play a role in the development of mental health deficits. The sibling relationship is the first dynamic developed between oneself and another individual similar in age, which in turn allows for the basis of socialization to be taught amongst siblings. Without siblings, how is this socialization fostered if not through successful interactions in school or with peers? Is an inconsistency in development and mental health deficits between only-children and those with siblings created due to this nature? After examining multiple studies, there were differing conclusions on whether or not only-children and individuals with siblings are more or less susceptible than the other, let alone how significant this difference is. In a study in which dimensions of time spent with others in contrast to time spent alone were investigated, Wikle et al. (2019) found that contentment was more associated with positive indifference and consistent with only-children. Only-children were found to be experiencing less happiness when spending time alone and with others when compared to their peers with siblings (Wikle et al, 2019. However, the definition of contentment as a dimension of the "positive low arousal" measure was only accounted for upon reflection of the researchers (Russel, 2003; Wikle et al., 2019). Essentially, only-children were experiencing less “positive high arousal," suggesting that there are less feelings of joy when spending time with others and alone (Russel, 2003; Wikle et al., 2019). Individuals with siblings, however, were much happier than their counterparts, which reflects the differences in how much joy individuals are experiencing based on their sibling count (or, a lack thereof) (Russel, 2003; Wikle et al., 2019). 
Therefore, having no siblings may cause a discrepancy in how children are interacting with their peers and environment.

In contrast to the previous study, Chen and Liu (2014) find that there was little to no difference in both psychosocial adjustment and academic achievement when comparing only children and individuals with one to two siblings. The only significant difference emerging from their research was found in a subgroup of "laterborn" adolescents, defined as individuals born any time following the firstborn child of the family (Chen \& Liu, 2014). Laterborn adolescents with more than two siblings within the household performed significantly worse than all subgroups within the study, although they noted that positive living conditions and resources contributed to higher academic achievement regardless of sibling count (Chen \& Liu, 2014). In another study of the interconnectedness between accessibility of resources and depressive symptoms, Chi et al. (2020) discovered that only children were significantly less depressed than their counterparts with siblings. Upon further investigation Chi et al. (2020) found that families with only one child were living in more affluent areas and had higher incomes than families with multiple children within the household. Another predictor of depressive symptoms within this study was gender, finding that girls were more inclined to have depressive symptoms than boys (Chi et al, 2020; McGuinness et al., 2012). Taken together, these studies suggest that greater resources (income, parental attention) are the factors that influence depression rather than whether or not a child has siblings.

Despite this research suggesting that individuals with and without siblings have little to no difference, Lockwood and colleagues (2001) found that children with siblings, especially in cases with high sibling warmth, were prone to be well-liked by their peers and be seen as "popular." If there was sibling conflict involved in these same dynamics, children with siblings 
were more likely to be well-adjusted to conflict outside of the home; their siblings provided the groundwork for conflict resolution, therefore providing these children with social skills that could aid them in developing stronger bonds with their peers (Lockwood et. al, 2001). This suggests that only children may not be fully adjusted due to a lack of social practice with children within their age range within the home.

\section{The Effects of Trauma Within Childhood Sibling Dynamics, or a Lack Thereof}

This literature review also aims to understand how trauma and the coping mechanisms to follow may be dependent on sibling count within a familial structure. Siblings could play a vital role in preventive measures such as shielding or comforting other children within the immediate family due to their shared lived experiences and potential practice of healthy coping mechanisms. This could also progress into a more negative route, as the behavior of siblings could negatively impact how the remaining children in the household manage their trauma. Only children exposed to trauma may be more or less likely to fall victim to unhealthy coping mechanisms when placed in solitude within the home, especially if the trauma endured involves the parents. Piotrowski and Cameranesi (2017) investigated the effects of intimate partner violence occurring within the home and how sibling warmth could play a mediating role on the severity of such trauma. The data gathered relied upon the birth order of each child, and whether or not the child was exposed to the trauma first-hand (Piotrowski \& Cameranesi, 2017). While acknowledging that there were multiple contextual factors necessary to truly account for the perceptions of sibling warmth, Piotrowski and Cameranesi (2017) found high levels of sibling warmth was a protective measure and discouraging of aggression between siblings when the relationship involved an exposed and non-exposed sibling. 
Examining more intense forms of trauma, such as the loss of a parent, children with siblings were reported in Hank's (2021) study with no mention of only children. Hank (2021) utilized a longitudinal study involving children who had lost a parent, and how they aged through early adulthood. Upon reflection, Hank (2021) found that siblings played a positive role in the aftereffects, such as emotional closeness increasing between the siblings. Although a period of conflict was noted in many of the participants, this emotional closeness persevered regardless and remained at similar, if not equal, levels at the time of the parent passing (Hank, 2021). Additionally, Hank (2021) found a lack of negative, long-term developmental consequences on behalf of the children, thus suggesting a correlation between sibling support and mental wellbeing as the children continued to develop into adulthood.

\section{Lasting Influences on Mental Health}

Examinations among adults reveal differing opinions on how siblings, or a lack thereof, could have detrimental effects on the mental health of individuals as they develop. This area of research has been heavily influenced by researchers within China, due to the introduction of the one-child policy. This policy, although gradually declining in its implementation, inspired research into the harmful effects of a sibling-lacking environment on children's mental health once introduced in 1979 (Potts, 2006). This policy’s intent was to decrease the rapidly growing population in China for the hopes of progressive economic growth (Potts, 2006). Regardless of intention, this policy ultimately fostered criticism and questioning on the implications this would have on a generation of children raised within environments without siblings. Consequently spurring an influx of research based upon individuals having gone through their own child development in China within this period created a myriad of deeper understandings of the dichotomy between only-children's mental health and that of their peers with siblings. When 
examining studies whose participants involved a higher percentage of Chinese individuals, is there a pattern noticed among implications of trauma when comparing adults with and without siblings experiencing trauma or negative emotions? Xie et al. (2021) considered this when examining Chinese and Japanese students' emotional responses when transitioning to a college dormitory living space. They found significant differences in coping mechanisms and levels of loneliness. Chinese students were found to be undergoing higher levels of loneliness than that of their Japanese counterparts, resorting to "social media" as a catalyst for comfort (Xie et al., 2021). Japanese students were more inclined to utilize social support by engaging in “interpersonal contacts, diversions, and pastimes" (Xie et al., 2021). Further informing this dichotomy is the demographic information provided in the study, which recorded that less than half of the Chinese students involved in the study came from households with more than one child (Xie et al., 2021). On the contrary, nearly $90 \%$ of the Japanese students within the sample had siblings (Xie et al., 2021).

Consistent with previous research, Roberts and Blanton's (2001) study involving personal accounts of adults with no siblings provided an existential consequence of being raised by oneself. Participants reported fears of being the final remaining member of their immediate family once their parents passed away, thus subjecting these individuals to "anticipatory sorrow" for which they would be alone in their grief and solitude (Mancillas, 2010; Roberts \& Blanton, 2001). Mancillas (2010) noted that there were not significant developmental differences, as only children were still functioning at equally healthy levels as their counterparts with siblings. Only "anticipatory sorrow" and carrying the weight of upholding the family following the death of parents that separated the experience of an individual with and without siblings. 


\section{Primary Prevention Programs}

The basis of primary prevention programs relies upon a cultural understanding of familial structures dependent upon ethnic and racial identities, which consequently influences stressors and expectations within the household itself. Much of the research on the topic of sibling dynamics and its impact on mental health lacked a diverse sample, primarily relying on populations of white or Asian descent.

Biases surrounding sibling birth order, as well as only children, appear to exist within professional workplaces. Primary care physicians were found by Stewart (2004) and Mancillas (2006, 2010, in press) as being more dismissive to or ignorant of the added stressors only children may be experiencing when confronting the "anticipatory sorrow" of upholding all familial duties preceding and following the death of their parents. Furthermore, a pattern of biases similar to that of clinicians was exhibited in therapists and educators, potentially causing misdiagnoses or negatively-fueled responses to genuine concerns expressed by clients or students (Mancillas, n.d., 2006, 2010, in press; Stewart, 2004). In Stewart's (2004) study, clinicians were provided a case on a man in early adulthood questioning his career choices, yet they were given different sibling counts; the cases noted that the man was either the oldest, middle, youngest, or only child, so as to challenge any biases based on sibling count within the clinicians' practice. Stewart (2004) found that there were significant differences, which included the man being seen as less likely to be upfront about these changing career perspectives to family members if he were perceived as an only child. Additionally, clinicians were more likely to diagnose the man with maladjustment problems if he were described as being the only child (Stewart, 2004). Mancillas (2006) offers a solution to this by advocating for well-rounded 
awareness of biases towards only children and the potential, exacerbating hazards that align with the role of the only child.

Other researchers emphasized this approach as well, focusing on the role of individuals outside of clinical settings as important sources of support that would increase positive mental health changes in the only child (Xu et al., 2019). People such as the child's peers in social groups, educators, and parents were regarded as having enough significance on the child to alter the trajectory of the child's ability to process emotions, thus potentially encouraging the strengthening of social skills such as conflict resolution and coping (Xu et al., 2019).

\section{Discussion}

Upon reflection of the research, I came to the conclusion that only children are susceptible to having difficulties with socialization, although these can be dependent on confounding factors. Having siblings, especially ones in which healthy relationships are formed, can be a vital step towards developing healthy conflict resolution skills and empathy (Lockwood et. al, 2001). Additionally, these sibling relationships can be a way to encourage seeking out help when individuals are struggling with mental health (Xie et al., 2021). The limitations of this conclusion are that only children are still able to foster healthy relationships outside of the home, given social settings such as participation in recreational activities through school, neighbors, or extended family. The findings of each study are dependent on these contextual factors, yet there are clearly certain behavioral trends that suggest only children may not have equal or similar coping mechanisms as their counterparts with siblings. All of the research I found on this topic was conducted with white, Chinese, or Japanese populations, thus allowing for the possibility that these results do not apply to other races or ethnicities outside of the ones discussed in this literature review. In order to properly address mental health deficits in youth depending on 
sibling count, we must understand the complexities of sociodemographic, racial, familial, and gendered struggles and how these operate when framing an argument. As a result, primary prevention programs can properly reflect the specificities and nuances of each individual case, which should be the biggest priority when aiming to reduce long-term harm. Depressive symptoms do not exist in a vacuum, simply dependent on the number of siblings. Multiple aspects continue to influence the susceptibility and predictability of mental illness in children, which must be accounted for when conducting research. Under the circumstances of outdated demographics catered towards white individuals and the concept of a "nuclear family," this research does not speak to many individuals that do not fit the specific population from which this research is derived from. A misinformed, or simply ignorant, perspective that does not reflect the different societal measures functioning as entirely probable catalysts for negative developmental consequences does more harm through misdiagnosis or misattribution unto the individual. To develop truly egalitarian programs, each individual's autonomy and experience must be honored.

We have seen the effects of research without understanding the confounding variables at hand, such as Russel (2003) and Wikle et al.'s (2019) examination of contentment as both a point of interest and difference in children with and without siblings' emotional status when spending time with others. By only honing in on the extremes of each emotional dimension (happiness or sadness), the nuance of emotion is successfully captured and allows for more complex theories to come forward. The research conducted by Russel (2003) and Wikle et al. (2019) also suggests the subversive detachment that only children may experience regarding peer connections could indicate an extremely important difference that remains unexamined. More research on these subtle differences could help indicate specific areas of emotional complexities within children 
that could inform clinicians, therapists, and family members that the child is in need of emotional support or primary prevention programs.

Considering the different variables accounted for in the research conducted by Xie et al. (2021), we must also consider that having siblings could potentially be a powerful precursor for greater sociability and lower depressive symptoms on the basis of loneliness being an antecedent to such behaviors and metal processes. One may suggest that these variables associated with Chinese students could have a reciprocal, interdependent relationship, given that being raised as an only-child does not grant the individual the ability to easily find a connection within the same age cohort in such close proximity. Therefore, only children may lean towards social media as a means to engage with others at a distance comfortable to their preference. Yet, the significantly higher levels of loneliness within Chinese students indicates that this very difference could be reliant on the lack of sibling relationships as a medium for developing bonds and seeking out help. Introducing therapeutic approaches that are more socially and culturally aware of the struggles would be a hopeful step in a more effective direction, although this approach is based in secondary prevention as the individual is not approached until after trauma or mental health issues have manifested. Primary preventive action could be encouraging individuals without siblings to create strong social support networks, thus allowing for a type of "replacement" for the sibling when handling such topics as being the sole survivor of a family.

Reflecting on the data at hand, there are conflicting findings; only children were reported as being more and less depressed than their counterparts with siblings, able to perform higher in social settings, and portray long-term symptoms of negative mental health patterns. There is still much to be understood about these dynamics, especially considering the cultural contexts that take specificities into account rather than focusing on the generalized, white-centered approach 
to research. The effect of siblings on mental health may not be fully understood until each individual experience is heard within all settings of life - that being the classroom, the clinical office, the home, etc. Despite much of this research being more representative of Western societies, the potential problems that only children face were brought to light and this awareness can lead to clinical practitioners, parents, and other adult figures in these children's lives providing more opportunities for healthy socialization and mental well-being. 


\section{References}

Adler, A. (1928). Characteristics of the first, second, and third child. Children, 3(5), 14.

Chen, Z., \& Liu, R. X. (2014). Comparing adolescent only children with those who have siblings on academic related outcomes and psychosocial adjustment. Child Development Research, 2014(3), 1-10. https://doi.org/10.1155/2014/578289

Chi, X., Huang, L., Wang, J., \& Zhang, P. (2020). The prevalence and socio-demographic correlates of depressive symptoms in early adolescents in China: Differences in only child and non-only child groups. International Journal of Environmental Research and Public Health, 17(2), 438. https://doi.org/10.3390/ijerph17020438

Hank, K. (2021). Linked in life and death: A note on the effect of parental death on sibling relations in young and middle adulthood. Journal of Family Issues. https://doi.org/10.1177/0192513x20985566

Higuera, V. (2019, October 23). Only child syndrome: Proven reality or long-standing myth? Healthline. https://www.healthline.com/health/parenting/only-child-syndrome

Lockwood, R. L., Kitzmann, K. M., \& Cohen, R. (2001). The impact of sibling warmth and conflict on children's social competence with peers. Child Study Journal, 31(1), 47. https://link.gale.com/apps/doc/A79147698/HRCA?u=s1185784\&sid=HRCA\&xid=693b

Mancillas, A. (2006). Challenging the stereotypes about only children: A review of the literature and implications for practice. Journal of Counseling \& Development, 84(3), 268-275. https://doi.org/10.1002/j.1556-6678.2006.tb00405.x

Mancillas, A. (2010). Only children. In J. Caspi (Ed.), Sibling development: Implications for mental health practitioners (pp. 341-357). Springer Publishing Company.

McGuinness, T. M., Dyer, J. G., \& Wade, E. H. (2012). Gender differences in adolescent 
depression. Journal of Psychosocial Nursing and Mental Health Services, 50(12), 17-20. https://doi.org/10.3928/02793695-20121107-04

Piotrowski, C. C., \& Cameranesi, M. (2017). Aggression by children exposed to IPV: Exploring the role of child depressive symptoms, trauma-related symptoms, \& warmth in family relationships. Child Psychiatry \& Human Development, 49(3), 360-371.

https://doi.org/10.1007/s10578-017-0755-7

Potts, M. (2006). China's one child policy. The BMJ, 333(7564), 361-362. https://doi.org/10.1136/bmj.38938.412593.80

Roberts, L. C., \& Blanton, P. W. (2001). "I always knew mom and dad loved me best": Experiences of only children. Journal of Individual Psychology, 57(2), 125-140.

Russell, J. A. (2003). Core affect and the psychological construction of emotion. Psychological Review, 110(1), 145-172. https://doi.org/10.1037/0033-295x.110.1.145

Stewart, A. E. (2004). Can knowledge of client birth order bias clinical judgment? Journal of Counseling \& Development, 82(2), 167-176. https://doi.org/10.1002/j.1556-6678.2004.tb00298.x

Wikle, J. S., Ackert, E., \& Jensen, A. C. (2019). Companionship patterns and emotional states during social interactions for adolescents with and without siblings. Journal of Youth and Adolescence, 48(11), 2190-2206. https://doi.org/10.1007/s10964-019-01121-z

Xie, Y., Kawata, Y., Kamimura, A., \& Shibata, N. (2021). Comparison of causes of loneliness and coping behaviors among Japanese and Chinese university student samples. Juntendo Medical Journal, 67(1), 46-59. https://doi.org/10.14789/jmj.2021.67.jmj20-oa08

Xu, H., Song, X., Wang, S., Zhang, S., Xu, S., \& Wan, Y. (2019). Mediating effect of social support in the relationship between childhood abuse and non-suicidal self-injury among 
Chinese undergraduates: The role of only-child status. International Journal of Environmental Research and Public Health, 16(20), 4023.

https://doi.org/10.3390/ijerph16204023 